Revista de Economia Política, vol. 33, no 2 (131), pp. 341-359, abril-junho/2013

\title{
Perspectivas das negociações entre o Mercosul e a União Europeia em um contexto de paralisia do sistema multilateral e da nova geografia econômica global
}

\author{
PATRÍCIA LUIZA KEGEL
} MOHAMED AMAL*

\begin{abstract}
Perst
Perspectives of the negotiations between Mercosur and the European Union in a context of multilateral system paralysis and new global economic geography. The aim of this paper is to scale the impact of changes in the patterns of international trade and Foreign Investment and how the shift in the world economic geography affects the relations between Mercosur and the European Union. The perception is that the outcome of negotiations between the two blocks is linked to the paralysis of the multilateral system and the European perspective of the economic dimension of the Agreement. The study suggests that the European Union faces conceptual and operational problems to establish clear goals and business strategies towards Mercosur and to insert them under a new global economic geography.

Keywords: Mercosur; European Union; multilateral trade system; globalization. JEL Classification: F53; F13.
\end{abstract}

\section{INTRODUÇÃO}

Vinte anos após a celebração do Tratado de Assunção, que criou o MERCOSUL, o contexto internacional apresenta uma realidade bastante diversa daquela

\footnotetext{
* Respectivamente Professora no curso de direito e no programa de pós-graduação em Desenvolvimento Regional na Universidade Regional de Blumenau - FURB, e-mail: plkegel@yahoo.com.br; Professor de Economia Internacional e Programa de Pós Graduação em Administração na Universidade Regional de Blumenau -FURB, e-mail: mohamedamal.amal@gmail.com. Submetido: 8/novembro/2011; aprovado: $25 / \mathrm{maio} / 2012$.
} 
que estimulou a criação de Acordos de Integração Regional. De um lado, é questionada sua eficácia em articular a cooperação entre Estados, na medida em que as particularidades do comércio internacional, fragmentado pela incapacidade de concluir a Rodada Doha da Organização Mundial do Comércio, dificultam a coesão interna de um bloco, como forma de fazer frente ao sistema comercial multilateral. De outro, o aprofundamento acelerado da globalização dá aos Estados novas formas de inserção internacional, além da integração regional.

Neste sentido, o presente artigo tem por objetivo dimensionar o impacto das mudanças nos padrões de comércio e Investimentos Diretos Externos sobre a dinâmica das relações entre o MERCOSUL e a União Europeia. Especialmente, pretende-se discutir os novos fatores que influenciam as negociações entre ambos os blocos, em particular as recentes mudanças no posicionamento do MERCOSUL nos fluxos internacionais de comércio, e o deslocamento do eixo de poder da geografia econômica rumo ao sudeste asiático.

Neste contexto, o objetivo deste trabalho é duplo: de um lado, averiguar se a integração regional proposta pelo MERCOSUL ainda é uma solução satisfatória de posicionamento comercial perante a globalização, e em que medida corresponde a um esquema tradicional de cooperação, em que as vantagens provenientes do acordo são suficientemente positivas para todos os atores envolvidos. De outro, verificar até que ponto o Acordo MERCOSUL - União Europeia, de maior amplitude do que um acordo meramente comercial expressaria apenas a necessidade mútua de acesso a mercados após o fracasso da Rodada Doha da OMC dentro da lógica do spaguetti bowl, ou se também, de forma mais estratégica, poderia ser utilizado como mecanismo de posicionamento conjunto perante a ascensão de novos players comerciais.

Em ambos os objetivos, será considerada a nova geografia comercial e econômica internacional, que alterou substancialmente os fluxos internacionais de comércio e investimento, reordenando a posição relativa de poder econômico e político dos Estados no cenário global. Ou seja, será considerada a crescente importância da China e do sudeste asiático em geral e seu impacto no espaço comercial e econômico da América Latina, particularmente do MERCOSUL.

Para tanto o trabalho será desenvolvido em quatro seções além desta introdução e das considerações finais. A primeira, com uma breve descrição do atual estágio do MERCOSUL, suas contradições e hesitações. Na segunda serão apresentadas as negociações com a União Europeia e a extensão de suas divergências. A terceira seção analisará a posição do MERCOSUL no contexto de alteração das relações econômicas internacionais, e na quarta serão avaliadas as implicações tanto destas alterações quanto da estagnação da Rodada Doha para a retomada das negociações de um eventual Acordo do MERCOSUL com a União Europeia. Por fim, as considerações finais apontam para a necessidade de reposicionamento estratégico de ambos os blocos, em um contexto internacional profundamente diverso daquele que gerou tanto o sistema multilateral de comércio quanto a dinâmica da integração regional. 


\section{A OPÇÃO PELA INTEGRAÇÃO REGIONAL VINTE ANOS APÓS O TRATADO DE ASSUNÇÃO}

Dentre as várias possibilidades de interação no âmbito das Relações Internacionais, destacam-se os esquemas de cooperação entre Estados. Originalmente, a cooperação pode ser definida como um conjunto de relações que não se encontram baseadas em fatores coercitivos, mas legitimadas dentro de um contexto de consentimento dos atores envolvidos, tendo por objetivo a obtenção de vantagens mútuas (Dougherty e Pfalzgraff, 2003, p. 642). Este tipo de esquema se desenvolve com força ao final da II Guerra, fundamentado na percepção generalizada da necessidade de atuação conjunta dos Estados (ou ao menos de uma parcela deles) para a superação de dificuldades comuns, correspondendo a Organizações Internacionais como as Nações Unidas ou alianças político-militares como a OTAN.

De forma mais estrita, os processos de integração regional que surgem a partir da década de 1950 podem ser avaliados, em um primeiro momento, como formas peculiares de cooperação entre Estados. Para Dougherty e Pfalzgraff (2003, p. 666), na sua dimensão processual, a integração econômica surge como o resultado de um conjunto de negociações principais, em que as elites nacionais entram em acordo sobre os objetivos básicos. A estes, seguem outras negociações subsidiárias destinadas a alcançar os objetivos acordados, podendo chegar, inclusive, ao estabelecimento de estruturas supranacionais ou de soberania compartilhada, cujo exemplo paradigmático é a União Europeia.

Por outro lado, a integração regional também pode ser considerada como uma forma de adensamento da interdependência entre Estados próximos, na medida em que a interligação das economias induz à redução das assimetrias e à distribuição dos ganhos econômicos e comerciais. Neste caso, o aumento da complexidade em que ocorre a interdependência é fundamentado na crença de que a relação custo/ benefício favorece esta modalidade especial de cooperação nacional, ao agregar também ganhos políticos aos benefícios decorrentes da integração econômica (Nye Jr, 2009).

Tais considerações envolvendo a cooperação e interdependência crescente entre Estados ganharam nova dimensão quando, a partir do inicio da década de 1990, a conjuntura internacional passa a ser caracterizada pela consolidação da globalização, a desregulamentação do mercado financeiro internacional e o aumento expressivo do comércio internacional pela via da liberalização comercial. Como ressaltado por Nye Jr (2009), as regras da economia internacional refletem as políticas e interesses dos Estados maiores ou hegemônicos. Desta forma, sob a perspectiva do aumento expressivo do comércio internacional na composição do PIB americano, e para coordenar os fluxos internacionais de comércio que cresciam a taxas maiores que o PIB mundial, os instrumentos de governança global foram reordenados através da consolidação das regras do comércio internacional na OMC.

Neste contexto de arquitetura comercial já impregnado pela concorrência entre Estados e regiões, e no qual era necessário articular a liberalização multilateral no âmbito da OMC, a formação de Acordos de Integração Regional (AIRs) possuía 
uma dupla vantagem. De um lado, por constituírem-se em exceção à Cláusula da Nação mais Favorecida, permitiam a manutenção de mercados domésticos protegidos. De outro, ao formarem um processo complementar ao sistema multilateral do comércio, estimularam níveis mais aprofundados de cooperação entre Estados de um mesmo entorno geográfico, na medida em que possibilitavam a seus membros o aprofundamento de temas como investimentos, compras públicas e concorrência.

No caso específico do MERCOSUL, seu processo de criação respondeu a duas tendências complementares do início da década de 1990. De um lado, a lógica da integração como suporte para um mercado ampliado, como nos moldes propostos pela Cepal desde os anos 1960. Nesta perspectiva, a integração proporcionaria o aumento de competitividade e internacionalização das empresas nacionais através da integração das cadeias produtivas, no âmbito de um marco jurídico estável e atraente para investimentos externos. Em segundo lugar, o bloco foi projetado para servir de plataforma de inserção internacional dos Estados em um ambiente econômico no qual a globalização começava a se intensificar. Neste caso, além das políticas de reestruturação dos fundamentos macroeconômicos e da abertura comercial recíproca, o MERCOSUL incentivou a concorrência entre vários setores econômicos nacionais dos principais países do bloco, possibilitando a sua preparação para o nível global de competição (Almeida, 2008).

No entanto, distintos fatores têm acentuado as limitações decorrentes de trasladar a experiência da integração europeia para outras regiões do mundo, particularmente no caso do MERCOSUL. Inicialmente, pelo fato de que as sucessivas crises na região acentuaram as assimetrias entre seus membros. A convulsão macroeconômica argentina de 2001 e sua consequente crise política e social induziram a um distanciamento maior da dinâmica de crescimento econômico dos dois principais parceiros do MERCOSUL. Assim, se em 1995, em dólares, o PIB brasileiro era de 770 bilhões, e o da Argentina era de 260 bilhões, ou seja, uma diferença de pouco mais de 2,5 vezes e que poderia ser explicada pela diferença populacional, em 2009 o PIB brasileiro foi de 1.6 trilhões de dólares e o PIB argentino de apenas 310 bilhões. ${ }^{1}$ Ou seja, mesmo descontando variações de câmbio, em especial a desvalorização do peso perante o dólar, a economia brasileira atualmente é pouco mais de 5 vezes maior que a argentina, refletindo a diferença de padrões de crescimento no período.

Tais crises afetaram igualmente os sócios menores. Uruguai e Paraguai não cresceram como esperado, dentre outros motivos, pelo direcionamento dos fluxos de capitais e investimentos rumo aos sócios maiores, agravando ainda mais as assimetrias. Por outro lado, ambos se ressentem das limitações decorrentes da adoção da Tarifa Externa Comum, que lhes retirou a necessária autonomia nas relações comerciais internacionais. Neste sentido, os ganhos decorrentes de uma cooperação aprofundada entre os Estados na manutenção ou aprofundamento do bloco não

\footnotetext{
${ }^{1}$ Os dados do PIB argentino e brasileiro são do Banco Mundial: http://data.worldbank.org/Acesso em outubro de 2011.
} 
vêm sendo considerados perceptíveis ou suficientes para superar os interesses divergentes entre todos os membros.

Mesmo neste contexto de crise econômica e poucas perspectivas comerciais, foram efetuadas algumas alterações na estrutura do bloco, com o objetivo de conceder maior eficiência, visibilidade e legitimidade ao seu quadro institucional. Em especial a transformação da Secretaria Administrativa em Secretaria Técnica, a criação da Comissão de Representantes Permanentes do MERCOSUL e de sua Presidência, a instalação do Tribunal Permanente de Revisão e do Tribunal Administrativo Laboral, o Fundo de Convergência Estrutural (FOCEM), e finalmente, o Parlamento do MERCOSUL.

Todas estas alterações, no entanto, mantiveram intocadas as estruturas jurídicas e institucionais de caráter intergovernamental que formataram o MERCOSUL desde seu inicio. Suas principais características são, basicamente, o princípio da igualdade soberana entre os Estados, a não ingerência nos assuntos internos dos Estados-partes, e a necessidade de consenso para adoção de qualquer decisão.

O resultado foi um acúmulo de instâncias superpostas, com baixa capacidade decisória, e diretamente exposta a distintas influências das conjunturas políticas e econômicas internas dos Estados-partes. Ao contrário da União Europeia, que conseguiu articular o processo de integração comercial e econômico com instituições supranacionais, a opção do MERCOSUL pela estrutura intergovernamental reflete ainda hoje, entre outras variáveis, as assimetrias econômicas, políticas e demográficas entre os Estados integrantes do bloco (Kegel, 2006). Nesta perspectiva, os limites do projeto de integração regional estariam muito mais vinculados aos problemas de ordem econômica e política interna de cada país, às percepções nacionais da importância estratégica do bloco, e à forma como as dificuldades domésticas afetam o grau de comprometimento nacional com a integração.

Apesar dos diferentes percalços institucionais e operacionais, o MERCOSUL nos últimos dois anos mostrou uma dinâmica positiva em direção à consolidação da União Aduaneira, e definição de medidas gerenciais para reduzir as assimetrias regionais e criar um ambiente favorável para a integração industrial de suas cadeias produtivas.

Três exemplos, entre várias medidas, são ilustrativos de tais esforços. O primeiro, que procura fortalecer a integração e o comércio intra-regional através da liberalização completa do comércio no setor de serviços até o ano de 2015. O segundo, relacionado à criação de um Fundo de Garantia para micro, pequenas e médias empresas, cuja finalidade é a garantia do aval dos empréstimos tomados, quando as atividades desenvolvidas visem a integração das cadeias produtivas. E o terceiro, que significou a adequação dos interesses dos Estados-partes ao aprovar medidas importantes para a consolidação da União Aduaneira, em especial a adoção do Código Aduaneiro do MERCOSUL, que uniformiza normas e procedimentos aduaneiros dentro do bloco. ${ }^{2}$

\footnotetext{
${ }^{2}$ Ver http://www.mercosur.org.uy. Acesso em fevereiro de 2011.
} 
Neste sentido, observa-se uma preocupação crescente com questões operacionais e administrativas relacionadas à gestão e aprofundamento dos mecanismos de liberalização comercial, de modo a estender este processo ao setor de serviços, por exemplo. Por outro lado, as medidas adotadas visam criar condições para o funcionamento efetivo da União Aduaneira, o que demonstra certo pragmatismo, pois, ao invés de estabelecer novas metas estratégicas, procura-se preservar o atual espaço de integração.

Nesta perspectiva, segundo Peña (2010), existem setores nos quais o MERCOSUL acumulou um estoque considerável de externalidades positivas. Em primeiro lugar, apesar de alguns retrocessos e indefinições, existe um conjunto de preferências econômicas e comerciais já pactuadas e que incidem sobre os fluxos de comércio e investimentos, possibilitando o adensamento do comércio intra-regional, a integração das cadeias produtivas e a atração de IDE externo ao bloco. Inclui, também, uma agenda múltipla (integração energética, infra-estrutura e meio-ambiente, por exemplo) que não se limita ao comércio e possibilita a transformação produtiva dos Estados da região. E por fim, existe o reconhecimento e identificação da "marca" MERCOSUL, tanto por parte das populações nacionais, quanto no contexto das relações internacionais.

Por outro lado, cumpre lembrar que os motivos para a integração regional não se esgotam em considerações vinculadas aos ganhos de escala em mercados ampliados, ou à possibilidade de coordenação macroeconômica (Chauffour e Maur, 2010). Neste sentido, os objetivos geopolíticos do MERCOSUL transcendem as questões meramente comerciais, na medida em que o bloco configura um ambiente de estabilidade política e econômica de âmbito continental, vinculado à construção de um projeto determinante para o aprofundamento da estabilidade democrática e governabilidade da região. Na expressão de Ferreira Simões (2010), não se pode perder de vista que o MERCOSUL possui um caráter de projeto político e estratégico, compartilhado pelos seus Estados e respectivas sociedades.

Desta forma, o MERCOSUL continuaria exercendo um papel importante, na medida em que mantém seus sócios integrados no âmbito de negociações comerciais ampliadas. Em especial, permite que as negociações com a União Europeia ocorram em um contexto birregional, agregando todos os Estados e não apenas aqueles com maior peso econômico e comercial. ${ }^{3}$

Após vinte anos de sua criação, o quadro resultante é, portanto, ambivalente. Inclui vários elementos que fragilizam o MERCOSUL, decorrentes tanto do desinteresse pela integração regional, quanto como resultado da incapacidade política e

\footnotetext{
${ }^{3}$ Para alguns analistas europeus (Gratius, 2011) poderia haver, por parte da UE, a tendência para orientar o desenvolvimento das relações com o MERCOSUL através do fortalecimento da Parceria Estratégica com o Brasil. Deste modo, os negociadores europeus poderiam reaproveitar a fórmula já utilizada com a Comunidade Andina, de celebração de um Acordo Marco Birregional, e acordos comerciais bilaterais com Países individuais. Este modelo teria a enorme vantagem de abrir o maior mercado da América Latina aos produtos industrializados europeus e, concomitantemente, permitiria à UE a manutenção do diálogo político e de cooperação com os demais Estados do bloco.
} 
operacional de implantar os objetivos propostos pelo Tratado de Assunção. Mas agrega, também, elementos positivos, relacionados aos renovados esforços em conservar um ambiente de articulação entre Estados em que permanece um consenso mínimo de objetivos comuns, em particular sua representação internacional conjunta e uma agenda que transcende a integração comercial.

\section{CONVERGÊNCIAS E DIVERGÊNCIAS NAS NEGOCIAÇÕES ENTRE O MERCOSUL E A UNIÃO EUROPEIA}

A evolução do MERCOSUL como bloco econômico mostra diversas tendências e padrões ao longo de duas décadas de sua existência, na qual o boom de integração comercial nos anos 1990 refletiu diretamente os efeitos da eliminação das barreiras tarifárias sobre o comercio intra-regional.

Em seu período inicial, a consolidação do MERCOSUL deveu-se, em grande parte, à convergência macroeconômica entre Brasil e Argentina, que, além de processos paralelos de democratização, liberalização comercial e privatizações, incluiu a paridade das taxas de câmbio do real e do peso argentino em relação ao dólar, permitindo uma relação de trocas comerciais relativamente equilibrada (Almeida, 2011). Já o crescimento durante o período de 1994 até o inicio de 2000 caracterizou-se por ser uma situação de abertura comercial intensa por parte de todos os Estados-partes, o que, por sua vez, estimulou tanto os fluxos de comércio intra-bloco, quanto extra-bloco. A coincidência dos dois processos (criação do MERCOSUL e política de liberalização comercial com terceiros) contribuiu significativamente para reduzir os efeitos do desvio de comércio, mostrando um bloco regional inserido na economia internacional.

Este contexto econômico favorável foi decisivo para a avaliação positiva do bloco sul-americano pelos órgãos europeus, a partir da percepção de que a constituição de uma União Aduaneira e posteriormente de um Mercado Comum levaria o MERCOSUL a trilhar a própria experiência integracionista europeia. Por outro lado, serviria de contrapeso à presença e aos interesses norte-americanos no continente, e, por fim, a dimensão de seu mercado interno, particularmente no Brasil e Argentina, favoreceria as empresas multinacionais europeias que já atuavam ou buscavam atuar nestes mercados.

O resultado foi um projeto visando a liberalização do comércio de bens e serviços até alcançar uma Área de Livre Comércio entre ambas as regiões, em conformidade com as disposições da OMC. É importante frisar que os objetivos não eram apenas comerciais, mas incluíam também o Diálogo Político entre ambos os blocos e a Cooperação nos âmbitos econômico, cultural e social.

Em julho de 2001, em um contexto de grande expectativa política e econômica, foram apresentadas as ofertas iniciais de ambas as partes, sendo a avaliação 
recíproca destas ofertas um forte indicativo dos motivos que levaram as negociações à estagnação. ${ }^{4}$

Segundo dados do Ministério do Desenvolvimento, Indústria e Comercio Exterior do Brasil (MDIC), a oferta europeia incluiu 90\% das importações do MERCOSUL, mas não os principais produtos de interesse nos setores agropecuários. Sua exclusão deveu-se ao fato de que se referiam exatamente a produtos agrícolas sujeitos, em sua maioria, às medidas protecionistas adotadas pela UE e ao conjunto de medidas de apoio constantes da Política Agrícola Comum. Já a proposta do MERCOSUL correspondeu a todo o universo tarifário. Deste total, porém, um conjunto substancial de itens foi considerado sensível, e não incluído nos cronogramas de desgravação de até 10 anos. Destes, a grande parte referia-se ao setor industrial, correspondendo a $68 \%$ das importações do MERCOSUL procedentes da UE.

Ou seja, ambas as propostas foram consideradas insuficientes, exatamente porque vinculadas a áreas econômica e politicamente sensíveis, nos respectivos cenários domésticos. O MERCOSUL com uma agroindústria bastante diversificada e altamente competitiva, exigia a abertura do setor agrícola europeu. Este, como é conhecido, é objeto de um arsenal de medidas protecionistas e de regulação de mercado, que apenas têm explicação na capacidade política dos atores envolvidos em fazer pressão sobre os respectivos governos nacionais. Neste caso, é interessante observar que a organização comum de mercado de determinados setores nem sempre é vantajosa para a totalidade dos Estados da UE, como o caso da Organização do Mercado de Bananas demonstrou. ${ }^{5}$

Já na perspectiva europeia, o MERCOSUL deveria rever sua lista de itens industrializados sensíveis, sobre os quais incidiam significativas alíquotas de importação. Ocorre que estes países, o Brasil em especial, desenvolveram seu complexo industrial nacional baseado na política de substituição das importações. Ou seja, historicamente, a existência de setores industriais nacionais fortemente protegidos da concorrência externa através de medidas protecionistas, sempre foi um consenso entre as elites econômicas e alta burocracia nacional (Rios e Iglesias, 2008). A exigência europeia, portanto, de abertura das importações de produtos industrializados, entrou diretamente em conflito com o status quo dominante e não teve prosseguimento.

Em 2004 as negociações foram retomadas, sendo que a proposta apresentada pela UE incluía $90 \%$ dos bens divididos em cinco grupos, com cronogramas diferenciados de desgravação de zero a 10 anos. Por sua vez, o MERCOSUL

\footnotetext{
${ }^{4}$ A descrição do histórico das negociações entre ambos os blocos encontra-se no site do Ministério do Desenvolvimento, Industria e Comercio do Brasil. Ver: http://www2.desenvolvimento.gov.br/sitio/secex/ negInternacionais/acoComerciais/mercUniEuropeia.php. Acesso em janeiro de 2011.

${ }^{5}$ A normativa comunitária sobre a Organização Comum de Mercado de Bananas, ao instituir a preferência de importação de bananas das ex-colônias europeias, em especial inglesas e francesas, provocou enormes prejuízos aos demais importadores europeus, particularmente os alemães.
} 
melhorou sua oferta em bens, elevando para $90 \%$ o conjunto dos bens incluídos no cronograma de liberalização, incluindo também algumas concessões na área de serviços. Segundo uma avaliação do impacto das negociações sobre ambos os blocos, elaborado naquela ocasião por Kume et al (2004), as estimativas de ganhos para a UE superavam em $40 \%$ os ganhos projetados para o MERCOSUL em geral, e o Brasil em particular. A causa estaria na insuficiente liberalização agrícola por parte da UE, gerando um desequilíbrio nas consequências econômicas sobre ambos os blocos.

Porém o fator determinante da interrupção das negociações entre ambos os blocos foi o fato de que tanto o MERCOSUL, enquanto bloco em seus países individualmente, como a União Europeia privilegiaram as negociações multilaterais na OMC como forma de aceder a mercados e, em particular, estabelecer mecanismos que reduzissem o grau de arbitrariedade na imposição de medidas anti-dumping, a eliminação de subsídios às exportações e a redução de subsídios domésticos para o setor agrícola (Rios e Iglesias, 2008).

Esta situação de estagnação nas negociações de ambos os lados foi significativamente abalada com o desencadeamento da crise financeira e econômica em fins de 2008, e motivou a reabertura das negociações em março de 2010. As ofertas de 2004 foram retomadas e melhoradas, mas, como já naquela ocasião, seria necessário que ambos os blocos oferecessem aberturas significativas nos seus respectivos setores econômicos considerados sensíveis.

\section{A INSERÇÃO DO MERCOSUL NOS ATUAIS FLUXOS INTERNACIONAIS DE COMÉRCIO}

A partir do final da década de 1990, as sucessivas crises internacionais e domésticas contribuíram significativamente para diminuir o ritmo de aprofundamento do processo de integração, tornando-o pouco significativo na estruturação da dinâmica econômica da região.

Entretanto nos últimos três anos, especialmente a partir da crise financeira global de 2008, ocorreu um processo de evolução do comércio internacional e dos fluxos de Investimentos Diretos Externos (IDE) no MERCOSUL e América Latina, que aponta para um conjunto de mudanças significativas.

Em primeiro lugar, porque a região não foi particularmente afetada pela crise de 2008, na medida em que não houve crise bancária ou necessidade de auxilio estatal para entidades financeiras em risco de insolvência, o déficit público mantém-se controlado e os fundamentos macroeconômicos permanecem estáveis nos principais países da região. Ou seja, a crise financeira global e seus desdobramentos recentes têm afetado de modo muito mais intenso os Países desenvolvidos, provocando uma séria retração econômica na União Europeia, a qual pode ser ilustrada na Tabela 1 abaixo, sobre o desempenho econômico e a estimativa de recuperação das principais economias mundiais. 
Tabela 1: Países e Regiões desenvolvidas e em desenvolvimento: contribuição ao crescimento mundial, 2008-2011. (Em pontos percentuais)

\begin{tabular}{lrrrr}
\hline Países e Regiões & 2008 & 2009 & 2010 & 2011 \\
\hline Países desenvolvidos & 0,12 & $-1,79$ & 1,55 & 1,22 \\
Estados Unidos & 0 & $-0,53$ & 0,56 & 0,53 \\
União Europeia & 0,15 & $-0,87$ & 0,36 & 0,35 \\
Japão & $-0,07$ & $-0,37$ & 0,23 & 0,08 \\
Outros & 0,04 & $-0,02$ & 0,4 & 0,25 \\
\hline Países e regiões em desenvolvimento & 2,74 & 1,27 & 3,46 & 3,18 \\
África subsaariana & 0,13 & 0,07 & 0,12 & 0,14 \\
América Latina e Caribe & 0,37 & $-0,15$ & 0,52 & 0,4 \\
Países em desenvolvimento da Ásia & 1,64 & 1,66 & 2,29 & 2,1 \\
China & 1,13 & 1,19 & 1,4 & 1,37 \\
Oriente Médio e Norte da África & 0,25 & 0,09 & 0,19 & 0,2 \\
Europa Central e Oriental & 0,11 & $-0,12$ & 0,15 & 0,12 \\
\hline Mundo & 2,87 & $-0,52$ & 5,01 & 4,4 \\
\hline
\end{tabular}

Fonte: Cepal (2011, p. 12), sobre a base de dados do FMI.

Dois conjuntos de dados são importantes de serem destacados. O primeiro diz respeito à situação de crescimento frágil dos países desenvolvidos. Mesmo que os Estados Unidos tenham uma participação projetada de $0,53 \%$ no PIB mundial em 2011, ela será menos da metade da participação individual da China projetada para o mesmo ano. Igualmente reveladora é a comparação das taxas de participação no PIB mundial entre a América Latina e Caribe (ALC) e a União Europeia. Desde 2008, a UE cresce a taxas menores daquelas registradas na ALC, e em 2009 a retração do seu PIB foi praticamente cinco vezes maior do que a retração ocorrida na América Latina. Por outro lado, os dados de 2011 são apenas estimativos e não levam em consideração o desenvolvimento recente das crises da dívida pública e do setor financeiro em alguns países europeus. Ou seja, existe uma possibilidade bastante real de ambas as crises se intensificarem nos próximos meses, levando a União Europeia, e a zona do Euro, a uma verdadeira recessão, enquanto que a ALC continua em uma trajetória de crescimento.

O segundo conjunto de fatores está vinculado ao crescimento das economias emergentes, em especial da chinesa, que alterou substancialmente a geografia econômica e comercial global, resultando em um efetivo deslocamento de poder relativo no cenário internacional, com implicações óbvias nas relações comerciais internacionais da ALC e do MERCOSUL em particular.

O fortalecimento do comércio da ALC com a Ásia e China pode ser expresso nos seus percentuais de participação nas exportações da região. A Ásia, que possuía no ano de 2000 uma participação de $5.3 \%$, em 2010 passou a representar $17.2 \%$ no total das exportações da América Latina. Ou seja, o crescimento foi tão intenso que 
a Ásia, inclusive, superou a União Europeia como destino das exportações da região. Também em relação às importações, as relações comerciais com a Ásia e China registraram o mesmo desempenho crescente. A participação da Ásia nas importações totais da América Latina, que em 2000 representava apenas $10.6 \%$ passou a representar 27.2\% em 2010, como pode ser observado na Tabela 2 abaixo. Em seu conjunto, tais dados demonstram a tendência crescente de desvio do eixo comercial estratégico da América Latina em direção à Ásia. (Cepal 2011, p. 17).

Tabela 2: América Latina e Caribe: Participação de sócios selecionados nas exportações e importações totais, 2000 e 2010. (Em percentuais)

\begin{tabular}{c|cc|cc|cc|cc|cc}
\hline & Ásia/Pacífico & \multicolumn{2}{|c|}{$\begin{array}{c}\text { Estados } \\
\text { Unidos }\end{array}$} & \multicolumn{2}{|c|}{$\begin{array}{c}\text { União } \\
\text { Europeia }\end{array}$} & \multicolumn{2}{|c|}{$\begin{array}{c}\text { América } \\
\text { Latina } \\
\text { e Caribe }\end{array}$} & \multicolumn{2}{|c|}{$\begin{array}{c}\text { Resto } \\
\text { do Mundo }\end{array}$} \\
\hline & 2000 & 2010 & 2000 & 2010 & 2000 & 2010 & 2000 & 2010 & 2000 & 2010 \\
\hline Exportações & 5,3 & 17,2 & 59,7 & 39,6 & 11,6 & 12,9 & 16 & 19,3 & 7,4 & 11 \\
\hline Importações & 10,6 & 27,2 & 50,4 & 29,1 & 14,2 & 13,7 & 15,3 & 22,7 & 9,5 & 7,3 \\
\hline
\end{tabular}

Fonte: Cepal, (2011), sobre base de dados estatísticos das Nações Unidas sobre comércio de bens e do FMI.

Consequentemente, portanto, os dados demonstram a diminuição do papel dos parceiros tradicionais da América Latina e Caribe no comércio internacional. No ano de 2000, os Estados Unidos e União Europeia absorviam juntos $71.3 \%$ (59.7\% EUA e 11.6\% UE) das exportações de bens e serviços da ALC. Em 2010, passaram a representar apenas $52.5 \%$ no total das exportações da região (EUA com $39.6 \%$ e UE com $12.9 \%$ ), de acordo com os dados da Cepal (2011, p.17).

Esta tendência geral da ALC também pode ser observada mais especificamente em relação aos Países do MERCOSUL, nos quais tanto as exportações para a Ásia e China, quanto as importações daquela região, cresceram a taxas médias superiores aos fluxos comerciais registrados com os EUA e a UE (Eclac, 2010). Neste caso, segundo algumas projeções (SELA, 2010), mantendo-se o atual ritmo de crescimento da demanda dos produtos provenientes da região nos Estados Unidos, na União Européia e no resto do mundo, e (se) a demanda chinesa crescer apenas metade do ritmo registrado nesta década, a China superaria a UE já em 2014 e passaria a ser o segundo maior mercado para a América Latina e Caribe.

\section{A RETOMADA DAS NEGOCIAÇÕES ENTRE O MERCOSUL E A UNIÃO EUROPEIA NO CONTEXTO DE PARALISIA DO SISTEMA MULTILATERAL E ALTERAÇÃO DA GEOGRAFIA ECONÔMICA MUNDIAL}

O ambiente político, econômico e comercial que deu origem ao GATT em 1947, e permitiu a criação da OMC em 1994, difere em grande medida do quadro atual. Em primeiro lugar, porque a emergência de novos players econômicos, particularmente a Índia e a China (e todo seu entorno), alterou o sentido dos fluxos 
de comércio e investimento, tornando a maior parte dos países desenvolvidos importadores de manufaturados e, recentemente, também de produtos com maior valor agregado tecnológico. Neste caso, também alguns países mais industrializados da América Latina como Brasil, Argentina e México, sentiram os efeitos da nova divisão internacional do trabalho, tanto pelo aumento das importações asiáticas em seus mercados domésticos, quanto pela perda de espaço nas exportações de produtos industrializados para outros mercados. E em segundo lugar, pela crise econômica que, iniciada em 2008 e ampliada em 2011, reforçou a desaceleração (ou eventual recessão) nos principais mercados desenvolvidos.

O resultado de ambas as tendências é uma desconfiança generalizada na ampliação da liberalização comercial, na medida em que esta diminui o espaço existente para a adoção de medidas protecionistas, as quais são vistas como mecanismos privilegiados de recuperação de empregos e de retomada da atividade econômica. Por outro lado, a agenda das negociações comerciais após o término da Rodada Uruguai tem refletido, em sua maioria, os interesses dos Países desenvolvidos, tais como o endurecimento nas regras de propriedade intelectual, compras governamentais e investimentos. Com a alteração das posições relativas de poder no comércio internacional a favor dos países emergentes, o empenho em negociar uma agenda de interesses conflitantes perdeu atratividade e energia.

Em decorrência desta situação, o atual sistema de comércio internacional está se tornando mais fragmentado, caracterizado por um número crescente de Acordos Comerciais Preferenciais (ACP), cuja notificação na OMC, até maio de 2011, alcançou a prodigiosa soma de 489 acordos, em que $90 \%$ são acordos de livre comércio, de alcance parcial ou preferencial (OMC, 2011). Ou seja, o comércio internacional está ocorrendo, cada vez mais, em um emaranhado de acordos preferenciais, que tendem a diminuir a importância do sistema multilateral. Esta lógica da fragmentação tem sido descrita como um "spaguetti bowl", na medida em que cada ACP gera uma relação comercial específica, com normas diferenciadas de acesso a mercados, regras de origem, prazos de desgravação tarifária, regras sobre investimento, propriedade intelectual e outros.

Outra alteração do contexto econômico internacional está relacionada ao tipo de articulação existente entre economias desenvolvidas e em desenvolvimento. Ou seja, as economias emergentes, historicamente, eram dependentes tanto econômica quanto financeiramente, das economias mais avançadas. Em especial as economias menores, ou menos diferenciadas, exportadoras de commodities, costumavam ser mais sensíveis às alterações das economias avançadas, e relativamente imunes aos demais países em desenvolvimento. No entanto, a nova geografia econômica mundial aponta para mudanças também neste aspecto, que segundo um estudo do Deutsche Bank (2011), sinaliza a interdependência crescente entre as economias emergentes e a criação de novos padrões de articulação, menos dependentes, com as economias maduras.

Esta interdependência está diretamente vinculada ao crescimento da China 
como ator econômico cada vez mais relevante, e à continuidade da crise econômica e financeira de 2008 nas economias desenvolvidas. Para o MERCOSUL, a implicação imediata foi a ampliação substancial do comércio regional com o sudeste asiático decorrente do aumento dos preços das commodities exportadas pela região. Segundo Castilho (2011), ao analisar os efeitos da crise de 2008 sobre o comércio exterior brasileiro, desde 2009 a China já é o principal parceiro comercial individual do Brasil. Em 2010 a região da Ásia absorveu 27\% das exportações brasileiras, das quais a China foi responsável por $15 \%$, contra $21 \%$ do total da União Europeia, 10\% dos Estados Unidos e 8\% da Argentina.

Consequentemente, houve, não apenas a diminuição da importância relativa do comércio com os parceiros tradicionais, ou seja, com a União Europeia e com os Estados Unidos, mas também a redução da sua importância econômica e influência política. Por outro lado, aumentou consideravelmente a dependência da região na manutenção do crescimento econômico chinês, responsável pelo aumento contínuo da demanda por commodities. Neste caso, a concentração das exportações em produtos primários para os mercados emergentes asiáticos criou uma situação de atrelamento das economias latino-americanas com aqueles mercados, cujo resultado pode significar o reinício de um novo ciclo de dependência econômica, mas desta vez com outros sócios, fora da esfera do capitalismo central.

Para a Cepal (2011, p.96), nas últimas três décadas, a região da América Latina e Caribe representou menos que 3\% do comércio total da União Europeia. Mesmo continuando a manter a segunda posição como sócio comercial da região (atrás dos Estados Unidos), a UE poderia perder tal posição para a China já em meados desta década. Por outro lado, o comércio europeu com a região está basicamente concentrado em alguns países, onde se destaca o MERCOSUL, que representa quase a metade do total. Com a adição do México, os cinco países representaram em 2010 61\% das exportações da ALC para a União Europeia e 69\% das importações.

No entanto é importante frisar que dentro desta dinâmica geral, as relações do MERCOSUL com a União Europeia apresentam uma vantagem a favor do bloco sul-americano se consideramos apenas o saldo da balança comercial. Os dados da Eurostat mostram que os países do MERCOSUL, em seu conjunto, apresentam um superávit comercial com um resultado que, em 2009, apontava para um excedente das exportações sobre as importações de 7,6 bilhões de Euros, com queda em 2010 para 4 bilhões de Euros, como consequência da crise global. Posteriormente houve uma recuperação significativa em 2011, registrando um valor de 5,2 bilhões de Euros de superávit em favor do MERCOSUL, como pode ser observado no Gráfico1 abaixo.

Por outro lado, embora os resultados da balança comercial sejam positivos para os países do MERCOSUL, a análise da pauta de exportações e importações entre os dois blocos aponta para uma estrutura de trocas que reflete um padrão assimétrico em sua composição. Ou seja, os países do MERCOSUL apresentam 
Gráfico 1: Balança Comercial do Mercosul com a União Européia (27).

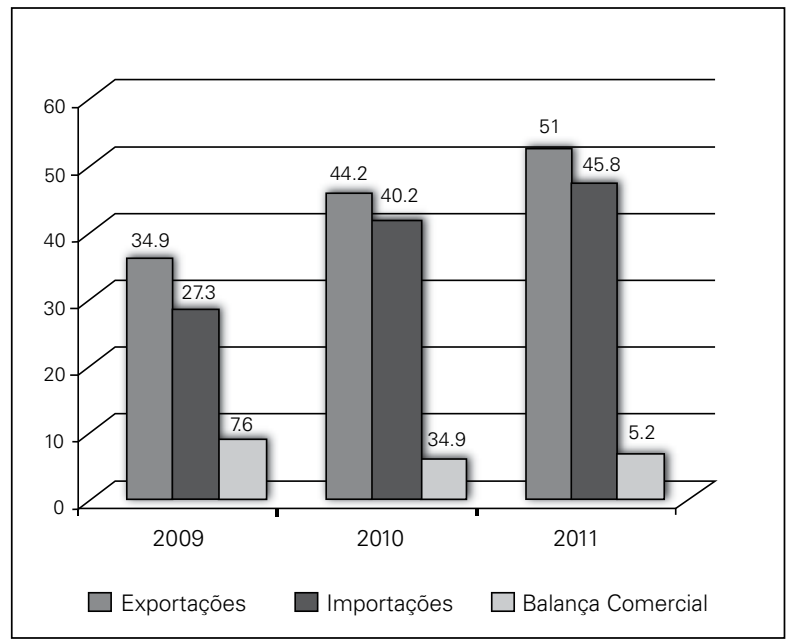

Fonte: Base de dados da Oficina de Estatística das Comunidades Europeias (EUROSTAT), 2012.

vantagens comparativas nos setores primários e agrícolas, enquanto que os países da UE apresentam uma pauta predominantemente concentrada em produtos manufaturados, tais como máquinas e equipamentos, equipamentos de transporte e química, dentre outros.

Desta forma, do total da pauta de exportações da UE (27) para o MERCOSUL, $87 \%$ são compostos por produtos manufaturados, como pode ser observado na Tabela 3 abaixo. Apesar da crise global, a participação dos setores de manufaturados mantiverem o mesmo desempenho na composição total do comércio inter-bloco. Da mesma maneira, se considerarmos a composição das trocas de produtos agrícolas e não agrícolas, os dados mostram que apenas $3.6 \%$ do total exportado pela UE para o MERCOSUL é composto de produtos agrícolas, enquanto que $94 \%$ dos produtos exportados são produtos não agrícolas.

Tabela 3: Exportações da UE (27) para o Mercosul por grandes grupos de produtos.

\begin{tabular}{l|cc|cc|cc}
\hline & \multicolumn{2}{|c|}{2007} & \multicolumn{2}{c}{2009} & \multicolumn{2}{c}{2011} \\
& Milhões de Euros & Milhões de Euros & $\%$ & Milhões de Euros & $\%$ \\
\hline Total & $28.155,90$ & 100 & $27.265,30$ & 100 & $45.820,20$ & 100 \\
Produtos primários & $2.366,10$ & 8,4 & $1.980,00$ & 7,3 & $4.275,40$ & 9,3 \\
Produtos manufaturados & $24.830,20$ & 88,2 & $24.082,00$ & 88,3 & $39.927,70$ & 87,1 \\
Outros produtos & 349,00 & 1,2 & 666,70 & 2,4 & 737,90 & 1,6 \\
\hline Produtos agrícolas & 925,20 & 3,3 & $1.075,60$ & 3,9 & $1.672,10$ & 3,6 \\
Produtos não agrícolas & $26.527,30$ & 94,2 & $25.495,30$ & 93,5 & $42.972,10$ & 93,8 \\
\hline
\end{tabular}

Fonte: Base de dados da Oficina de Estatística das Comunidades Europeias (EUROSTAT), 2012. 
Enquanto isso, a pauta de exportações do MERCOSUL para a UE (27) mantém-se predominantemente concentrada em produtos primários. Desta forma, em 2007 a participação dos produtos primários era de $71.5 \%$ no total das exportações para a UE, e, em 2011, a participação dos produtos primários aumentou para $75 \%$, como pode ser observado na Tabela 4. Paralelamente, a participação dos produtos manufaturados registrou uma leve queda nos últimos anos, de $28 \%$ em 2007, para apenas $24 \%$ em 2011.

Se diferenciarmos as trocas entre produtos agrícolas e não agrícolas, as exportações do MERCOSUL para a UE (27) são representadas por $56 \%$ de produtos não agrícolas, como pode ser observado na Tabela 4 abaixo.

Tabela 4: As exportações do MERCOSUL para a UE (27) por grandes grupos de produtos

\begin{tabular}{|c|c|c|c|c|c|c|}
\hline & $\begin{array}{c}2007 \\
\text { Milhões de Euros }\end{array}$ & $\%$ & $\begin{array}{c}2009 \\
\text { Milhões de Euros }\end{array}$ & $\%$ & $\begin{array}{c}2011 \\
\text { Milhões de Euros }\end{array}$ & $\%$ \\
\hline Total & $42.267,60$ & 100 & $34.931,30$ & 100 & $50.950,80$ & 100 \\
\hline Produtos primários & $30.204,20$ & 71,5 & $25.547,80$ & 73,1 & $38.130,50$ & 74,8 \\
\hline Produtos manufaturados & $11.788,90$ & 27,9 & $9.105,60$ & 26,1 & $12.355,20$ & 24,2 \\
\hline Outros produtos & 135,20 & 0,3 & 176,00 & 0,5 & 218,80 & 0,4 \\
\hline Produtos agrícolas & $19.086,50$ & 45,2 & $18.411,20$ & 52,7 & $21.852,50$ & 42,9 \\
\hline Produtos não agrícolas & $22.968,10$ & 54,3 & $16.324,10$ & 46,7 & $28.684,00$ & 56,3 \\
\hline
\end{tabular}

Fonte: Base de dados da Oficina de Estatística das Comunidades Europeias (EUROSTAT), 2012.

Mesmo neste contexto de composição assimétrica de pautas exportadoras entre ambos os blocos, é necessário observar que a dinâmica dos fluxos de Investimento Direto Externo europeu continua priorizando o espaço da ALC e MERCOSUL como seu principal destino.

$\mathrm{Na}$ Tabela 5 abaixo pode ser observado que a ALC, com exceção do período 2003-2005, manteve-se em posição superior à da Ásia como destino do IDE europeu, superando inclusive a China nesta competição internacional pela atração dos investimentos das empresas multinacionais europeias. Mesmo que, segundo a Cepal (2011), parte dos investimentos europeus tenha sido realizada em alguns países da América Central e Caribe (Antíguas, Bahamas, Bermudas, Ilhas Caimã entre outros), com o propósito de aproveitar as facilidades fiscais destes países.

Importa ressaltar que, sem considerar os centros financeiros do Caribe, o estoque de IDE da União Europeia na ALC está concentrado em poucos países. Neste caso, as três maiores economias da região receberam $80 \%$ dos fluxos de IDE acumulados entre 2000 e 2009 (Cepal, 2011, p.91). Por outro lado, dados da Comissão Europeia (2011) demonstram que em 2008, o estoque de investimento direto europeu no MERCOSUL somou 167,2 bilhões de euros. Ou seja, mesmo com a crise econômica e financeira (ou exatamente por sua causa), as multinacionais europeias mantiveram o MERCOSUL, e o Brasil, como principal destino de seus investimentos externos. Não cabe, nos limites deste trabalho, investigar as causas de tal preferência. No entanto, tais estratégias empresariais deveriam ser levadas 
Tabela 5: União Europeia. Distribuição dos fluxos de Investimentos Diretos Externos segundo destino, 2000-2009 (Em porcentagem do total de IDE da União Europeia no Mundo).

\begin{tabular}{l|ccccc}
\hline & $2000-2002$ & $2003-2005$ & $2006-2008$ & 2009 & $2000-2009$ \\
\hline União Europeia & 62,0 & 64,1 & 59,2 & 38,7 & 59,4 \\
\hline Estados Unidos & 14,0 & 7,4 & 14,1 & 17,3 & 12,4 \\
\hline Ásia & 5,7 & 7,1 & 5,2 & 6,1 & 6,0 \\
\hline América Latina e Caribe & 7,1 & 4,5 & 6,0 & 15,4 & 6,8 \\
\hline Total & 100,0 & 100,0 & 100,0 & 100,0 & 100,0 \\
\hline
\end{tabular}

Fonte: Cepal, 2011, sobre a base de dados da Oficina de Estatística das Comunidades Europeias (EUROSTAT)

em consideração no contexto mais amplo das renovadas negociações entre ambos os blocos.

Por sua vez, cálculos da Comissão Europeia (2011) estimam em 9 bilhões de Euros, 4.5 bilhões para cada bloco, os ganhos decorrentes de um acordo de livre comércio entre ambas as regiões. Sob a perspectiva europeia, a inserção do setor automotivo na oferta do MERCOSUL, por exemplo, teria como resultado imediato o aumento da vantagem competitiva das empresas automobilísticas europeias em relação à suas concorrentes norte-americanas e japonesas. O prosseguimento das negociações, no entanto, vem novamente sofrendo reveses. Pela parte europeia, pela exigência de abertura de $100 \%$ do mercado de bens industrializados, tal como já negociado com a Colômbia e o Peru. Porém o fator decisivo para a reticência europeia vem sendo a pressão exercida por um grupo de países, que liderados pela França, se opõe firmemente à ampliação das concessões agrícolas. Mesmo que, sob outra perspectiva que não a da mera liberalização comercial, o aumento das importações do MERCOSUL tivesse por consequência o barateamento dos produtos agrícolas para o consumidor europeu.

Já pelo lado do MERCOSUL, mesmo que a abertura europeia do setor de carne bovina e de frangos, por exemplo, trouxesse ganhos consideráveis à agroindústria do bloco, também não existe muita disposição em negociar temas alheios à esfera da liberalização comercial. Em particular são considerados sensíveis temas como compras governamentais, propriedade intelectual e indicação geográfica, serviços e investimentos, e desenvolvimento sustentável. Este último, especificamente, sempre foi considerado como sendo uma abertura para a imposição de barreiras não tarifárias, tanto nas negociações birregionais, quanto na OMC. Por outro lado, subsistem dificuldades de composição dos interesses comuns aos Estados-partes, em especial o neoprotecionismo argentino como política deliberada de reindustrialização nacional, e a incorporação plena da Venezuela, refratária a acordos de liberalização comercial.

Mesmo com tais obstáculos, é importante frisar que a manutenção de índices elevados de investimentos diretos externos europeus na região indica que a desaceleração econômica, pela qual a UE passa desde 2008, não afetou as decisões de investimentos de suas empresas multinacionais. Neste sentido, a manutenção do dinamismo nas economias do MERCOSUL constitui-se em um atrativo especial 
para a atração de IDE, na medida em que as EMNs europeias intensificam sua atuação tanto para suprir a demanda nos mercados locais aquecidos, quanto para utilizá-los em suas estratégias de complementaridade produtiva.

Este dado é extremamente importante no âmbito das negociações birregionais, pois sugere que é possível a integração produtiva e o desenvolvimento de cadeias de valor transregionais (Cepal, 2011). Neste caso específico, se a indicação de origem for conjunta, a formação de cadeias produtivas integradas pode ser fortemente impulsionada pela celebração de um acordo entre o MERCOSUL e a União Europeia, constituindo um fator de estímulo à recuperação e desenvolvimento industrial de ambas as regiões.

Ou seja, mesmo que a atual composição das pautas exportadoras entre ambos os blocos indique a continuidade de um padrão primário exportador por parte da ALC e MERCOSUL em relação à UE, os dados do IDE europeu na região permitem considerar que a intensificação da atividade das empresas multinacionais europeias no espaço sul-americano opere como um vetor de aproximação. Ademais, a posição estratégica da ALC nos fluxos de IDE europeus proporciona uma dinâmica nova nas relações entre as economias, permitindo criar um clima empresarial favorável à retomada das negociações sem a cláusula de impasse que representa a questão agrícola.

\section{CONSIDERAÇÕES FINAIS}

As regras comerciais multilaterais que constituem o quadro jurídico em que ocorrem as trocas comerciais entre todos os membros da OMC aos poucos vão cedendo a primazia às normas derivadas de acordos preferenciais. Ocorre que as normas do sistema multilateral procedem de uma negociação em que todas as partes participam, e em que diversos interesses entre seus membros são levados em consideração. Neste sentido, mesmo estando longe do ideal, as normas da OMC oferecem uma base jurídica comum nas relações comerciais entre Estados com diferentes pesos econômicos relativos no cenário comercial e econômico global. Ou seja, o conjunto normativo multilateral, exatamente porque vincula todos os Estados, impede que posições de poder relativas sejam utilizadas nas relações comerciais internacionais. $\mathrm{Na}$ ausência deste sistema, Estados com menor grau de influência econômica podem ser facilmente induzidos a celebrar acordos comerciais em termos nem sempre vantajosos.

Neste contexto de fragilização do sistema multilateral de comércio e de celebração de acordos preferenciais potencialmente assimétricos, os processos de integração regional dificultam a exposição direta dos países menores a pressões por maior liberalização comercial unilateral, e recuperam um espaço de articulação entre Estados baseado na cooperação.

Desta forma, podemos sugerir que o MERCOSUL, mesmo que os resultados em termos de crescimento e desenvolvimento não tenham sido iguais para todos os países, continua a desempenhar um papel relevante para seus membros. No 
âmbito estritamente comercial, na medida em que permite a representação externa conjunta de seus membros, ampliando sua capacidade de negociação e poder relativo em um quadro de transformações globais. Mas também como um espaço de coordenação e cooperação (nem sempre perfeitas), em que a manutenção de um ambiente que agrega outros objetivos além dos estritamente comerciais, permite que as instituições conjuntas sejam utilizadas como forma de minimizar as consequências das assimetrias, através, por exemplo, do FOCEM e dos programas de incentivo à integração produtiva.

Em relação ao longamente negociado acordo com a União Europeia, é possível supor vantagens para ambos os lados. No caso específico do MERCOSUL, torna-se urgente posicionar-se em relação à reorganização da geografia econômica e comercial global, na qual o papel da região começa a ficar circunscrito ao de fornecedor de matérias primas e importador de produtos industrializados. Neste caso, um acordo com a União Europeia possibilitaria a ampliação de sua participação naquele mercado, inclusive ao deixar de ser alvo de eventuais medidas protecionistas. Por outro lado, o montante de investimentos diretos efetuado pelas empresas europeias na região permitiria a integração produtiva e o aumento do comércio inter-regional de produtos industrializados. É indispensável, contudo, a consolidação conceitual da integração, a ser traduzida no aprofundamento dos mecanismos de liberalização comercial e ampliação do espaço de cooperação entre os Estados. Neste caso, não podem ser toleradas exceções à circulação de fatores produtivos, concomitantemente à implantação de políticas de estimulo econômico nos países menores.

No caso da União Europeia, fortemente abalada pela crise financeira e em retração econômica, um acordo com o MERCOSUL permitiria assegurar acesso privilegiado aos seus produtos nos maiores mercados da América Latina, reforçando sua base industrial, expandindo a atuação de suas empresas multinacionais e diminuindo a pressão competitiva dos produtos chineses na região. Entretanto, é necessária a construção de um consenso interno, que articule as posições conjuntas de seus 27 Estados-membros e que confira visibilidade à dimensão do acordo. Ou seja, significa o reconhecimento das mudanças da geopolítica comercial desde a implantação do MERCOSUL, e suas implicações.

Desta forma, a reorganização econômica mundial e a estagnação da Rodada Doha, em cuja conclusão tanto o MERCOSUL quanto a UE depositaram a maioria de seus esforços, impelem ambos os blocos a redirecionarem suas estratégias para posicionarem-se tanto em relação à expansão das exportações asiáticas, quanto à perda de mercados resultante do aumento de acordos preferenciais.

Em uma perspectiva estratégica, portanto, um Acordo Birregional permitiria a ambos os blocos posicionarem-se em relação às mudanças globais que transformaram a China e a Ásia nos mercados mais importantes para a recuperação e o crescimento mundiais. Para o êxito das negociações, no entanto, é fundamental que o MERCOSUL e a União Europeia modifiquem não apenas as posições de negociação comercial, mas, acima de tudo, sua percepção política recíproca, de forma a consolidar os interesses comuns e estabelecer novos padrões de cooperação regional. 


\section{REFERÊNCIAS BIBLIOGRÁFICAS}

Almeida, Paulo Roberto de (2011) "Seria o MERCOSUL reversível? Especulações teóricas sobre trajetórias alternativas concretas". Revista Universitas Relações Internacionais vol. 9, n.1.

Almeida, Paulo Roberto de (2008) Integração Regional e Inserção Internacional dos Países da América do Sul: evolução histórica, dilemas atuais e perspectivas futuras. São Paulo: Instituto Fernando Henrique Cardoso; Santiago do Chile: Corporación de Estudios para Latinoamérica (Cieplan), 2008. In: http://www.ifhc.org.br. Acesso em julho de 2011.

Castilho, Marta (2011) "Impactos da crise econômica internacional sobre o comércio exterior brasileiro", in Luciana Acioly e Rodrigo leão, orgs. Crise Financeira. Mudanças Estruturais e Impactos sobre os Emergentes e o Brasil. Brasília: IPEA.

Cepal. Comisión Económica para América Latina Y Caribe. Panorama de la inserción internacional de América Latina y el Caribe 2010-2011. Chile: Nações Unidas. In: http://www.eclac.org/cgibin/ getProd.asp?xml=/comercio/agrupadores_xml/aes168.xml\&xsl=/agrupadores_xml/agrupa_listado.xsl. Acesso em outubro de 2011.

Chauffour, Jean-Pierre; Maur, Jean-Christophe (2010) "Beyond market access. The new normal of preferential trade agréments", The World Bank Institute. Policy Research Working Paper 5454. In: http://elibrary.worldbank.org/docserver/download/5454.pdf?expires=1319647778\&id=id\&a ccname=guest\&checksum=B663E2D8F5980C70846EFF2D2CA18362. Acesso em outubro de 2011.

Deutsche Bank (2011) "Research Talking point. BRICs \& G-3. Changing interaction, emerging complementarities. In: https://www.dws-investments.com/EN/docs/research/BRIC_G3.pdf. Acesso em março de 2011.

Dougherty, James; Pfalzgraff, Robert L. (2003) Relações Internacionais. As teorias em confronto. Lisboa: Gradiva.

Eclac - Economic Commission for Latin America and the Caribbean, (2010). Latin America and the Caribbean in the world economy, Chile: United Nations. Acessado em agosto/2011 em http:// www.eclac.org/cgibin/getprod.asp?xml=/publicaciones/xml/6/40696/P40696.xml\&xsl=/comercio/tpl-i/ 1 .

Gratius, Suzanne (2011) “Brasil y Europa hacia 2015”, Policy Brief n. 49. Acessado em fevereiro/2011 em http://www.fride.org/publicacion/886/brasil-y-europa-hacia-el-2015.

Kegel, Patrícia Luiza (2006) “Aspectos jurídicos e institucionais do MERCOSUL”, em Núcleo Estratégico do MERCOSUL - NEMER. CEBRI - Documentos de Trabalho. Rio de Janeiro: Centro Brasileiro de Relações Internacionais.

Kume, Honório; Piani, Guida; Miranda, Pedro; Castilho, Marta (2004) “Acordo de Livre Comércio MERCOSUL - União Europeia: uma estimativa dos impactos no comércio brasileiro”, http:// www.anpec.org.br/encontro2004/artigos/A04A082.pdf Acesso em julho de 2011

Nye Jr, Joseph S. (2009) Cooperação e Conflito nas Relações Internacionais, São Paulo: Editora Gente. Penã, Félix (2010) "Es posible una visión realista pero positiva de la integración latinoamericana y del Mercosur?” Revista Diálogo Político. Konrad Adenauer Stiftung.

SELA - Latin American and Caribbean Economic System (2010) XXXVI Regular Meeting of the Latin American Council. Caracas, Venezuela. http://www.sela.org/attach/258/EDOCS/ SRed/2010/12/T023600004599-0-recent_developments_in_economic_relations_between_China_and_LAC.pdf. Acesso em julho/2011.

Simões, Antonio José Ferreira (2010) "MERCOSUL: Uma visão estratégica às vésperas de seu $20^{\circ}$ Aniversário”, em http://www.cebri.com.br/midia/documentos/simoes_mercosul_out_10.pdf. Acesso em abril / 2011.

Rios, Sandra Polónia; Iglesias, R. (2008) “Anatomia do boom exportador e implicações para a agenda de negociações comerciais do Brasil”, in: Veiga, Pedro da Motta (Coordenador) Comércio e Política Comercial no Brasil. Desempenho, interesses e estratégias. São Paulo: Singular.

Veiga, Pedro da Motta; Rios, Sandra Polóniam (2010) “A emergência asiática e a América Latina: implicações econômicas atuais e prospectivas”, em http://www.plataformademocratica.org/ Arquivos/A\%20emergencia\%20asiatica\%20e\%20a\%20America\%20Latina.pdf. 